\title{
Imperative Demand to Establish the Marine Aesthetics Subject with the Strategy of Empowering China with Oceans and under the Background of Strategic South China Sea
}

\author{
Jiafa Wang ${ }^{1, a^{*}}$ and Xing Wei, \\ ${ }^{1}$ Hainan Tropical Ocean University Institute of Education Hainan Sanya 572022 \\ ${ }^{2}$ Hainan Tropical Ocean University Department of Russian Hainan Sanya 572022 \\ awangj168@163.com, bweixing118@163.com \\ ${ }^{*}$ The corresponding author
}

Keywords: Construction; Marine aesthetics; Necessity; Possibility; Discipline system

\begin{abstract}
The marine aesthetics subject was first proposed to be established as early as 4 year ago with some scholarship following this subsequently, but until today, there is no a little sign to establish the subject of marine aesthetics. After the $18^{\text {th }}$ congress of the CPC when the strategic target of establishing a maritime power was proposed, Strategic South China Sea was also put on the agenda because South China Sea is China's biggest blue territory and Hainan, with rich marine resources, has absolute geographical advantage. Under such special background, it is imperative to establish the subject of marine aesthetics. This paper elaborates on the necessity and possibility of establishing the marine aesthetics subject respectively, and finally proposes the structure and system of establishing the marine aesthetics.
\end{abstract}

\section{Introduction}

As early as in 2011, some scholars suggested establishing the marine aesthetics subject from the three major ecology: "poetic natural marine ecology", "harmonious social marine ecology" and "characteristic cultural marine ecology". [1]

In 2012, one scholar said three key issues should be emphasized in establishing marine aesthetics: the research subject of marine aesthetics, its inherent rules should be grasped, and application of the subject must be given full play to in order to serve the society's aesthetic education. [2]

In 2014, some scholars strongly called for the establishment of China's marine aesthetics subject, suggesting "marine aesthetics subject should be established, analyzed and summarized from four aspects: reality, religion, science and art as well as the interaction with other cultures in marine experiences." They believe that China's marine aesthetics is not a new kind of aesthetics, but a new field of aesthetics - ocean. Or it can be said that with the contemporary evolution of the Chinese culture, oceans are becoming the focus of culture and the focus of aesthetics. Marine aesthetics is just to apply the aesthetic principle to the ocean. "There is a long and tough way to go for China to establish its own marine aesthetics". [3]

The above scholars' opinions on establishing marine aesthetics provide important theoretical guiding significance for China to re-examine the relationship between China and human beings' outlook on ocean as well as studying the relationship between Chinese aesthetic mentality and ocean the Strategy of Empowering China with Oceans and Under the Background of Strategic South China Sea.

Reality tells us that it has already been 5 years since scholars first call for the establishment of marine aesthetics subject, but there is no a little sign to establish the subject of marine aesthetics. Nor there are few articles conducting in-depth analysis of the rich aesthetic connotation of the marine culture (less than 20 articles on the National Knowledge Infrastructure (NKI), so the situation is by no means optimistic.

The 21st century is a century of oceans, and it is an urgent demand of development of the human beings to establish marine aesthetics subject as well as the development of the current era. Also, it is an urgent demand for the Chinese people to realize the dream of empowering the country with 
oceans and strategic South China Sea. Therefore, it is imperative to establish the marine aesthetics subject, and such imperativeness can be elaborated on from two aspects: necessity and possibility.

\section{Necessity to Establish the Marine Aesthetics Subject}

It Is China's Political Demand of the Strategy of Empowering China with Ocean and Strategic South China Sea to Establish and Learn the Marine Aesthetic Subject, Which Is of Important Realistic Significance to Improve People's Understanding of Ocean Knowledge and Marine Aesthetics as well as Protect the Marine Environment. The marine culture can empower a country and make China become stronger; the marine aesthetics can make China more beautiful. With strong ocean, a country can become strong and with beautiful ocean, a country can become more beautiful. Such idea must become the consensus of our Chinese. Ocean is where life originates on the earth as well as a world of beauty. The reality requires us to establish the marine aesthetics subject so as to realize the dream of empowering China with ocean proposed at the $18^{\text {th }}$ congress of the CPC and complete the task of aesthetic education proposed by the Ministry of Education. Empowering China with ocean needs to support from ocean culture, and marine aesthetics, as an important part of the ocean culture, plays an important role in empowering China with oceans. However, we happen to have no marine aesthetics subject, which indicates that we do not have a full understanding of the ocean's contribution to the entire human beings. Where is the beauty of oceans? It is still in blankness as what role it plays to the society, college culture and aesthetic education at colleges, especially ocean universities, so it is imperative for us to discover, promote, explore, integrate and study marine aesthetics to make it become a systematic subject as well as improve humanistic quality of the entire human beings through aesthetics education and serve for the establishment of ocean universities.

Establishing the Marine Aesthetics Subject is Humans' Spiritual Demands to Appreciate the Beauty of Oceans. Oceans cover a total area of three hundred and sixty million square kilometers, about $71 \%$ of the total surface of Earth. The South China Sea is a marginal sea of Southern China and a part of the Western Pacific Ocean. It was called Zhang Sea and Fei Sea before the Qing Dynasty and after that it is renamed the South China Sea. Covering an area of 3.56 million square kilometers, the South China Sea is not only an important sea transport route, but is also rich in oil and natural gas. On one hand, the sea meets humans' rich material demands with its abundant material resources, and on the other hand, it satisfies people's spiritual demands to appreciate beautiful resources.

Sea is the most beautiful part on the globe with its suffocating, surprising, breathtaking and fascinating beauty.

The beauty of oceans refers to the aesthetic attributes of various forms of the ocean, which has great appreciative value and is an important subject for people to appreciate beauty.

Main features of the oceans' beauty lie are vastness, deepness and variability. Blue water, beautiful beach, clean bay, pretty shore and rich resources are the external image of the oceans' beauty. Gorgeous deep seawater, strange and colorful fish, shellfish, algae and coral as well as the wonderful underwater world are the internal image of the ocean's beauty. It is just like a mysterious world in the fairy tale which can arouse people's infinite longingness.

The ocean consists of diverse beautiful forms and the ocean is the integrity and hymn of various forms of beauty: bold, graceful, masculine and feminine, delicate, harmonious and strange, etc.

Faced with the various forms of aesthetic attributes of the ocean, what aesthetic consciousness will be produced on people's mind? What is the form and type of the ocean's beauty? What role does the ocean's beauty play in human life? What strategic significance does the research into ocean's beauty have with the strategy of empowering China with oceans and under the background of strategic South China Sea? In order to study the various above problems, it is necessary to establish the marine aesthetics subject to satisfy people's demand to appreciate the beauty of oceans. Humans need not only the material space provided by the ocean, but also regard oceans as their spiritual space. With the overall progress of the society, humans not only pursue a poetic residence on land, but also begin to embrace the ocean - to face oceans, integrate with oceans and love 
oceans.

Necessity to Establish Marine Aesthetics Subject due to Pollution to the Beautiful Environment of Oceans. The current marine environment is worrying. In order to pursue various interests, instead of protecting the beautiful ocean, humans crazily damage the beautiful environment and ecology of oceans, unscrupulously deprive countless living lives, bringing great disaster to marine lives and turning the beautiful oceans into a bloody and fierce world. The last clean world of the ocean no longer exists, so is the most beautiful world.

In order to make China and the South China Sea beautiful, we need to have beautiful South China Sea. Otherwise, it is just an empty talk to empower China with oceans and realize strategic South China Sea. The government should establish rules and regulations to protect the beautiful environment of oceans and strength establishing the ocean culture at the same time. Establishing the marine aesthetics subject is just one of the magnificent projects to establish the ocean culture.

Establish the Marine Aesthetics Subject has Great Practical Significance to Constructing Beautiful International Travelling Island of Hainan. The CPC General Committee General Secretary Xi Jinping said in April 2013 when he inspected Hainan that green mountains, clean water, clear sea and blue sky are the most precious things in constructing the international travelling island, so we must cherish and take meticulous care of them. It can be said that green mountains, clean water, clear sea and blue sky are the sign to construct beautiful international travelling island of Hainan [4]. Xi said that more efforts should be made to "produce more green mountains and protect the blue sky", which means we need to create a beautiful Hainan Island with the meaning and principle of aesthetics, and in order to create a beautiful Hainan Island, we need to first create a beautiful world of sea.

The how to create a beautiful world of sea? First of all, the government needs to set up rules and system and Strengthen the enforcement of the "Ocean Law" to protect the ocean with laws by honoring protecting oceans and condemning those actions destroying oceans.

Secondly, we need to invest some funds to set up project to study and write the subject of marine aesthetics and organize teams to conduct in-depth exploration of the rich aesthetic resources of the South China Sea as soon as possible. Hainan is an island surrounded by the South China Sea with unique and heavy tropical marine culture. While the heavy marine culture gives firth to the unique and beautiful landscape of ocean and form rich aesthetic resources, so it is an important content for us to establish the marine aesthetics subject.

Thirdly, set up marine aesthetics course and localized course to preach sea knowledge to primary and middle school students, making the former become a general course of college students and the later become an enlightenment education material about the ocean for children [5].

Fourthly, organize college students to publicize the beauty of oceans on campus, at the scenic spot and the marine operation areas to promote knowledge and theory about the beauty of oceans and the great significance of the ocean's beauty to empowering China with culture, strategic South China Sea and constructing international travelling island of Hainan.

Fifthly, publicize the marine aesthetics subject to the mass and travelers so that everyone can know it.

Sixthly, government at each level of Hainan needs to create oceanic scenic spot at their respective region so as to make oceanic scenic spot ubiquitous and become the artistic work of the ocean's beauty, make travelers impressed by the beauty of oceans, even forgetting to leave, and make the beauty of oceans deeply rooted in the eyes, on the minds and within the hearts of travelers so as to become their aesthetic awareness and actions to love beauty.

Judging from this, in order to construct beautiful international travelling island of Hainan, it is very necessary for us to establish the marine aesthetics subject.

\section{Possibility of Establishing Marine Aesthetics Subject}

Oceans Have Abundant Aesthetic Resources, and Humans' Rich Practices to Explore the Beauty of Oceans have Made It Possible to Establish the Marine Aesthetics Subject. As has been said by Mr. Zhang Fa: "Scarce ocean has produces infinite imagination about ocean; ocean is 
magnificent because it contains not only various treasures from the Maritime Silk Road, but also fairy tales and legends." [6] Forming and developing the relationship between human beings and marine aesthetics has provided premise for the establishment of marine aesthetics subject.

Beautiful ocean scenery, ecology, artistic beauty, nationality beauty and economic beauty have provided premised for establishing marine aesthetics subject. The relationship between human beings and the ocean develops from a utilitarian one to an aesthetic one and is deepened, i.e., human beings' abundant practices of exploring the beauty of oceans have provided aesthetic psychologic basis for establishing marine aesthetics subject.

Currently, there are more than 30 ethnic groups living on Hainan Island: Han, Li and Miao, etc. These ethnic groups have their own experience of travelling across the sea and accumulated their own history of appreciating the beauty of oceans. These books about the history of appreciating the beauty of ocean with the characteristics of different ethnic groups have provided us with limitless source of materials when we establish the marine aesthetics subject.

Establishing Marine Aesthetics Subject Is the Inevitable Result of Developing and Refining the Aesthetics Subject and Theories. Ever since 1750 when Baumgarton established the aesthetics subject, this subject has undergone a development history of hundreds of years, from simple to complex and from coarse to refined.

The sign of refinement is that it has evolved from one subject to a lot of sub-branches or subjects, such as philosophical aesthetics, ethical aesthetics and analytical aesthetics, as well as special aesthetics like art aesthetics, film aesthetics, music aesthetics and painting aesthetics, etc. As one scholarship said: "This subject has infinite and open development because beauty can be seen everywhere. It can be analyzed at both micro and macro level. [7]" Sub branches of aesthetics or other sub divisions can be established in many relevant fields, so it is also possible to establish marine aesthetics.

With Marx Aesthetics Ideology as the Guidance and Solid Aesthetic Theory as the Support, Solid Ideological and Theoretical Basis has Been Laid for the Establishment of Marine Aesthetics. The development history of human beings' aesthetics shows that Marx aesthetic though is scientific and progressive because it elaborates on various issues of aesthetics with Marx opinions and methods, especially about the essence of beauty and art.

This is the guiding ideology of our socialist society to establish aesthetics of the proletariat, so it is the leader and soul as well as our solid ideological basis to establish the marine aesthetics at present.

Basic aesthetical principle established based on such ideology is the theory of aesthetics, sense of beauty, aesthetic morphology, artistic theory of aesthetics and aesthetic education, which has made it possible to establish the framework of the marine aesthetics subject.

The Support from Aesthetics, Sub Branch of Aesthetics and Marine Science has Provided Solid Theoretical Basis for the Establishment of Marine Aesthetics Subject and Made It Possible. Marine aesthetics is also a branch of aesthetics as well as a sub branch of it. Therefore, in order to establish marine aesthetics, it is both necessary to refer to the basic principle and method of aesthetics and principle of the marine science so as to conduct systematic academic research into the marine aesthetics. Marine sociology helps to provide reference for establishing marine aesthetics and the marine society with harmony as the core. "The reason why the Marine has become an aesthetic object is to enter people's aesthetic activities, because it has a certain social significance to human beings, to the aesthetic subject, such as that, affirmation or negation of meaning. [8]" Marine aesthetics research in reference on the basis of marine science, using the principle of ecology and aesthetics, by analysis of the aesthetic characteristics of the marine ecosystem, marine ecological aesthetic study of comprehensive, system, strive to communicate the intrinsic link between aesthetic research as the marine ecosystem of the natural science and the humanities, to provide new research ideas for the relationship between man and nature, man and the sea, explore human and marine harmony, ways and methods of constructing the poetic dwelling living home and spiritual home.

It has Been Proposed at the 18th Congress of the CPC the National Strategic Target of 
Constructing a Marine Power and Strengthening Constructing the Marine Culture, Which has Provided an Actual Basis of Favorable Climatic, Geographical and Human Conditions for the Establishment of Marine Aesthetics. One, follow the global trend. In the report of the $18^{\text {th }}$ congress of the CPC, the communist party proposed the magnificent goal of making China become a country with powerful marine economy. Turning China from a marine giant into a marine power is both the token of the time and the necessary for the Chinese nation to become prosperous.

Two, General Secretary Xi emphasized at the $8^{\text {th }}$ group learning of the CPC Central Committee Political Bureau that in order to gradually achieve the strategic goal of becoming a marine power, all the CPC members need to further care for ocean, recognize and understand ocean to promote China to constantly achieve new results in establishing a marine power [9].

Three, on October 10, 2015, the Ministry of Education held a forum, requiring all relevant departments to implement the "Opinions on Comprehensively Strengthening and Improving Aesthetic Education" issued recently by the State Council" and strength weak links in aesthetic, stressing the importance of carrying out aesthetic education at school.

The target of the $18^{\text {th }}$ congress of the CPC of turning China into a marine power, General Secretary's attention on such strategic deployment and the Ministry of Education's emphasis on aesthetic education have laid realistic condition and basis for the establishment of marine aesthetics as well as powerful political guarantee.

\section{Definition of and Relationship between Aesthetics and Marine Aesthetics}

What Is Aesthetics? It is a subject studying all the beautiful phenomenon on the world. Ever since subjects were first created, there were various opinions about this concept and none of them was universally recognized. Li zehou thinks, "at present there are mainly three kinds of views of Chinese pop, (1) aesthetics is the study of beauty; (2) the aesthetics is the study of general principles of philosophy of art; (3) the aesthetics is to study the aesthetic relationship of science. [10]" However, some major concepts are universally acknowledged: the essence of beauty, subjects and objects of beauty, and the aesthetic feeling is the sense of beauty. It is a subject studying the relationship between human beings and the world, i.e. the research subject is human beings' activities of appreciating beauty. The target of aesthetics is to reveal and elaborate on the phenomenon of appreciating beauty, improve people's spiritual status and make life become beautiful. Generally, it includes aesthetical theory, sense of beauty, aesthetic morphology, aesthetic art and aesthetic education, etc.

What Is Marine Aesthetics? It is a branch and sub division of aesthetics that regards the ocean as the research subject so as to study how this subject affects the formation of people's aesthetic awareness and the rules. Marine aesthetics is an integral part of the aesthetics subject.

Marine aesthetics mainly studies the following contents: it is a subject to appreciate the beauty of the "ocean" by taking "beauty of ocean" as the research subject and exploring the essence and characteristics of ocean, aesthetic psychology, morphology and aesthetic education as the research content. What is the purpose of establishing the marine aesthetics? The necessity has been elaborated from four aspects in the above, so there is no other comment here.

\section{Prospect for the Marine Aesthetic System and Framework}

The System of Marine Aesthetics can be Divided into Six Major Parts. the first is the introduction, which is mainly about the definition of marine aesthetics and its research subject, research contents and research method. The second is the theoretical support to establish marine aesthetics, which provides the philosophic and aesthetic basis of marine aesthetics as well as the relationship between each subject. The third is the features of marine beauty and people's marine aesthetic mentality, which mainly allows people to realize the basic features of marine beauty: variable, gorgeous, mysterious and diversified, as well as let people know how the marine beauty is produced. The fourth is to learn and grasp the morphology of marine beauty. It divides the marine beauty into five types: beautiful scenery, beautiful ecology, artistic beauty, ethnic beauty, and 
aesthetic economy. The fifth is the relationship between marine aesthetics and people's life, and the sixth is marine aesthetics and aesthetic education.

\section{The Basic Framework Is as Follows:}

Chapter One Introduction

Chapter Two Marine Aesthetics and Theoretical Support

Chapter Three Features of Marine Aesthetics and Aesthetic Psychology

Chapter Four Morphology of Marine Aesthetics

Chapter Five Aesthetic Relationship between Marine Scenery and Travelling to Hainan

Chapter Six Marine Aesthetics and Aesthetic Education

\section{References}

[1] M. Zhou, ZH.M. Liang. Proposition, Definition and Theoretical Composition of "Marine Aesthetics": Beauty and Monthly Times (the second half). Vol 10 (2011) No. 6, p. 20-23

[2] Y.X. Cen. Discussion of Marine Aesthetics: Journal of Yanshan University (Philosophical and social science edition), Vol 13 (2012) No. 1, p. 105-107.

[3] F. Zhang. How to Establish the Chinese Type of Marine Aesthetics: Qiushi Journal, Vol 41 (2014) No. 3, p. 115-123

[4] Information on http://politics.people.com.cn/n/2013/0410/c1024-21090468.html

[5] J.L. Qu. Report on the development of China's maritime culture. (Social Sciences Academic Press, China 2014.) p. 283

[6] Y.N. Zeng. On the Generation and Development of Aesthetics: Journal of Jining University. Vol 8 (1998) No. 5, p. 12-15

[7] Hu Jingzhi. The Aesthetics of Literature and Art. (Peking University Press, China 2000.) p. 22

[8] Information on http://www.gov.cn/xinwen/2014-10/13/content_2764226.htm

[9] Li Zehou. Three kinds of aesthetic monographs. (Tianjin Social Sciences Publishing House, China 2003) p. 443

\section{Introduction to the Author:}

Wang Jiafa (1955-), male, from Lingshui, Hainan. Dean of Institute of Education, Hainan Tropical Ocean University, professor, famous college teacher in Hainan. Research Direction: artistic aesthetics, especially the construction of artistic theory textbooks. Recently, she turns to research ethnic aesthetics.

\section{Introduction to the author:}

Wei Xing (1985-), female, Xianyang Shanxi, Hainan Tropical Ocean University, Department of Russian, doctor, research direction: Russian culture. 